\title{
Impacto de la recaudación de impuestos y el pib del ecuador en el contexto de la pandemia covid -19 en la industria de alojamiento y servicios de comida. Un análisis coyuntural en el período 2020
}

\author{
Mayra Lucía Reyes Pacheco \\ https://orcid.org/0000-0002-3520-1510 \\ mayrar@uhemisferios.edu.ec \\ Facultad de Ciencias Económicas y Empresariales \\ Universidad Hemisferios \\ (Quito-Ecuador) \\ Melissa Jazmín Segovia Peñafiel \\ mjsegoviap@estudiantes.uhemisferios.edu.ec \\ Facultad de Ciencias Económicas y Empresariales \\ Universidad Hemisferios \\ (Quito-Ecuador)
}

\section{RESUMEN}

Todos los estados requieren generar recursos económicos para cubrir con todas las exigencias y necesidades públicas, siendo parte así del Presupuesto General del Estado. La tributación es la forma de obtener dichos ingresos para el cumplimiento de sus fines sociales. Estos tributos son recaudados de acuerdo con la normativa legal emitida desde la Constitución del Estado y que se producen gracias a la actividad económica que se genera por los sectores que conforman el aparato productivo del país. En año pandémico la economía del Ecuador tuvo su impacto negativo en la reducción del PIB la misma que fue resultado de varias Industrias que fueron afectadas por las medidas económicas, de bioseguridad y salud adoptadas en este período. Dentro de la presente investigación se ha tomado en cuenta la Industria de Alojamiento y Servicios de Comida como un referente de un sector en el cual pudo sostenerse durante el año pandémico. El análisis del PIB como indicador macroeconómico permite evidenciar el crecimiento económico de un país y el aporte de cada Sector dentro del indicador, por ello es importante analizar en año pandémico, cómo se comportó el aporte del Sector de la Industria de Alojamiento y Servicios de Comida en el PIB y mirar el impacto económico mediante la Recaudación Tributaria y las Ventas de dicho sector.

Palabras clave: PIB; impuesto a la renta; IVA; VAB; impuestos; pandemia covid-19. 


\title{
Impact of ecuador's tax collection and gdp in the context of the covid -19 pandemic in the accommodation and food services industry. A situation analysis in the 2020 period.
}

\begin{abstract}
All states need to generate economic resources to cover all public demands and needs, thus being part of the General State Budget. Taxation is the way to obtain said income to comply with your social fines. These taxes are collected in accordance with the regulations issued by the State Constitution and are produced thanks to the economic activity generated by the sectors that make up the country's productive apparatus. In a pandemic year, Ecuador's economy had a negative impact on the reduction of GDP, which was the result of several Industries that were affected by the economic, biosafety and health measures received in this period. Within this research, the Accommodation and Food Services Industry has been considered as a reference of a sector in which it could be sustained during the pandemic year. The analysis of GDP as a macroeconomic indicator allows evidence of the economic growth of a country and the contribution of each Sector within the indicator, for this reason it is important to analyze in a pandemic year, how the contribution of the Sector of the Accommodation and Food Services Industry behaved in GDP and look at the economic impact through Tax Collection and Sales of this sector.
\end{abstract}

KEYWORDS: GDP; Covid-19 pandemic; GVA; taxes, IVA; Rent Tax

Artículo recibido: 02 noviembre. 2021 Aceptado para publicación: 28 noviembre 2021 Correspondencia: santiagou@uhemisferios.edu.ec Conflictos de Interés: Ninguna que declarar 


\section{INTRODUCCIÓN}

Las consecuencias de la aparición del coronavirus han sido catastróficas, no solo por las muertes y contagios que ha provocado, sino también por su impacto en la economía de los países. La economía ecuatoriana ya en el segundo trimestre del 2020 el covid-19 era un escenario negativo con una caída del 12,4\% del Producto Interno Bruto con respecto al 2019, dada a la suspensión de las actividades productivas, este decrecimiento ha sido la mayor caída que ha tenido el país desde el 2000. El Banco Central del Ecuador indica que teniendo en contexto la pandemia, esta caída es explicada por el decrecimiento del $18,5 \%$ en la inversión y 15,7\% en exportaciones de bienes y servicios. (Banco Central de Ecuador , 2020) A raíz del confinamiento los resultados macroeconómicos y sociales han sido poco alentadores, para el mes de diciembre del 2020 el PIB del Ecuador habría caído en un 7,8\% ochocientas mil personas pasaron a vivir en condiciones de pobreza extrema. Según datos del Instituto Ecuatoriano de Seguridad Social (IESS), hubo un total de doscientas cuarenta mil desafiliaciones entre marzo y mayo, donde el $80 \%$ pertenecen al sector privado y solo el $40 \%$ a la ciudad de Quito. Según proyecciones, Ecuador estuvo recibiendo al comienzo del año 20212.1 millones de "nuevos pobres" sumando total 6.4 millones, lo cual representa el 37\% de la población del país. (El Telégrafo, 2020)

El sector del turismo está compuesto por las variables de acuicultura y pesca de camarón, actividades de servicio financiero, transporte y alojamiento y servicios de comida, sin embargo, los que más atribuyen son las industrias de transporte y alojamiento y servicios de comida. Según el World Travel \& Tourism Council, el sector de turismo contribuyó al PIB nacional en el 2019 con un 6\% y a nivel global con un 10\%. Las contribuciones que genera este sector son importantes para dinamizar la economía del país ya que tiene una extensa cadena productiva y es considerada como una fuente importante de divisas para la economía dolarizada dejando un saldo positivo de US\$ 512 millones en el tercer trimestre del año 2019. (Lucero, 2020)

La Industria de Alojamiento y Servicio de Comidas es parte del sector estratégico del turismo priorizado por la Secretaria de Planificación y Desarrollo del Ecuador (Senplades) y por el gobierno nacional. La industria cuya clasificación del CIIU que está representada por la letra "I” para el año 2020 aportó al PIB nacional con US\$ 2'388.63 millones de dólares, es decir, representó el 2,2\% y ocupó el puesto 12 de 46 ramas de las actividades económicas. (Sánchez, Vayas, Mayorga, \& Freire, 2020) 
El VAB (Valor Agregado Bruto) de esta Industria redujo en un 11,70\% con respecto al año 2019, según el MINTUR se debió a que el ingreso de los extranjeros cayó en un 98\% como resultado del cierre de fronteras por la emergencia sanitaria lo que incidió en una menor demanda en hoteles, restaurantes y servicios relacionados. (Banco Central de Ecuador , 2020) Además, el IESS señaló que, a inicios del confinamiento entre marzo y mayo 2020, el sector de Alojamiento y Servicios de Comida tuvo una desvinculación de 24.612 trabajadores. (Planifica Ecuador, 2020)

La Recaudación Tributaria de la Industria de Alojamiento y Servicios de Comida en el año 2020 fue de $\$ 119,462,741$ que representó el 1.04\% frente a la Recaudación Nacional con una tasa de variación de - 28.53\% a comparación del año 2019.

Las Ventas generadas por este sector en el 2020 fue de \$1,487,936,336 que representó el $1.75 \%$ de las Ventas totales de todas las Industrias y cuyo decrecimiento fue del $40.96 \%$ frente al 2019.

\section{ANTECEDENTES}

Según el informe del Banco Central de Ecuador emitido en mayo del 2021, el impacto que ha tenido el Covid-19 en la economía del país ha sido catastrófico. En primer lugar, se señala que las pérdidas desde marzo, mes donde empezó el confinamiento y las restricciones impuestas por el Gobierno, hasta diciembre alcanzaron un total de USD 16.3817 millones, de las cuales el $78.1 \%$ pertenece al sector privado y el total de pérdidas representó el 16.6\% del PIB 2020.

Los resultados presentados por el BCE reflejan que por el efecto de la pandemia el PIB cayó en $6.4 \%$ a nivel de Industrias y que la Industria más afectada fue la de Alojamientos y Servicios de Comida cuyo VAB cayó en un 26.2\% seguida por Enseñanza y Servicios Sociales y de Salud con un 15.1\%. (Banco Central del Ecuador, 2021)

En el artículo publicado por la Revista Gestión se puede conocer que durante la emergencia sanitaria el sector turístico cuyas actividades como alojamiento y servicios de comida se vieron sumamente afectadas dado que tanto empresas grandes como pequeñas estuvieron paralizadas por meses puesto que el teletrabajo no es una opción para los negocios involucrados en esta cadena productiva (Revista Gestión, 2020). Además, la caída significativa del VAB de los sectores estratégicos que conforman el turismo se debe en gran parte por el cierre de aeropuertos internacionales y por la cuarentena como medida para controlar el coronavirus. Como se menciona en el artículo "Impacto financiero del 
covid-19 en el turismo ecuatoriano", el turismo es un pilar fundamental para la economía del país dada a su extensa cadena productiva y gracias a su diversificación es capaz de generar fuentes de empleo directos, permitiendo así a miles de ecuatorianos tener una vida digna. Sin embargo, para el año pandémico cientos de restaurantes y hoteles se vieron forzados a cerrar sus instalaciones lo que provocó despidos masivos en este sector. En este artículo se menciona que en el 2020 hubo una disminución drástica del 68.2\% en cuanto a entradas internacionales de personas no residentes ocasionando un efecto negativo en la entrada de divisas del $60.2 \%$ y también en la balanza turística del $63.5 \%$ a comparación del año 2019. (Becerra, Vega, \& Orellana, 2021)

De esta manera el Covid-19 ha tenido un impacto devastador en la economía y en el empleo del país donde la Industria del turismo se vio perjudicada por las medidas adoptadas para contener la pandemia y que cambió drásticamente el modo de operar de los negocios y las vidas de las personas que forman parte de esta Industria.

\section{Estado del Arte}

La emergencia sanitaria mundial por causa de la Covid-19 ha impactado directamente en el desarrollo económico mundial, afectando varios aspectos como la movilidad de las personas y el normal funcionamiento de establecimientos productivos y comerciales.

El BCE dentro de sus previsiones macroeconómicas de 2020, publicadas en enero de este año, sitúa al alojamiento y servicios de comida en el puesto 12 de 46 ramas de actividades económicas, con una contribución de \$2.388,63 millones de dólares en 2020 (2,2\% del PIB). De acuerdo a datos del Ministerio de Turismo - MINTUR, el número total de establecimientos registrados en 2019 es de 24.382, de los cuales el 85,3\% pertenecen a alojamiento y servicios de comida con un crecimiento promedio de 2,9\% entre $2011 \mathrm{y}$ 2019. Al analizar la contribución de las Ventas generadas por este Sector, mediante el sistema SAIKU del SRI, en las declaraciones 104, el reporte de ventas de las actividades de alojamiento para estancias cortas, mostraron un total de \$477,20 millones de dólares en 2019 , una variación de $2,7 \%$ respecto al 2018 y un crecimiento promedio de 3,0\% entre 2011 y 2019. (Sánches, Vayas, Mayorga, \& Freire, 2020)

El Producto Interno Bruto es el valor de bienes y servicios totales producidos por un país en un tiempo definido con el fin de medir la riqueza creada en ese periodo cuya tasa de variación es considerada como el principal indicador de la evolución de la economía de un país. El índice del PIB corresponde a la suma del Valor Agregado Bruto (VAB) de 
todas las unidades de producción residentes más los otros elementos del PIB conformados por: impuestos indirectos sobre productos subsidios sobre productos derechos arancelarios, impuestos netos sobre importaciones e Impuesto al Valor Agregado (IVA). El VAB consiste en la diferencia entre la producción y el consumo intermedio.

El Producto Interno Bruto (PIB) del Ecuador, en el 2020 en términos constantes, totalizó USD 66.308 millones, lo que representa una caída de 7,8\%, según los datos de las cuentas nacionales trimestrales. De acuerdo al Banco Central del Ecuador este comportamiento se explica por: i) decrecimiento de 11,9\% de la formación bruta de capital fijo; ii) disminución de 7,0\% del gasto de consumo final de los hogares; iii) reducción del gasto de consumo final del gobierno general de $6,1 \%$ y, iv) contracción de las exportaciones de bienes y servicios en $2,1 \%$. De su parte, las importaciones de bienes y servicios fueron menores en 7,9\% a las registradas en el año 2019. (Banco Central del Ecuador, s.f.)

La contribución económica productiva de las empresas en el desarrollo económico del país durante la pandemia fue abocado por varios problemas que se tuvieron que ir superando paulatinamente, es así que la contribución de ingresos en la Industria de Alojamiento y Servicios de Comida fue de $1.75 \%$ del total de Ingresos registros en el SRI por este Sector.

\section{Según el SRI, la recaudación por los siguientes rubros se conceptualiza de la siguiente} forma:

- Impuesto a la renta. Se aplica sobre aquellas rentas que obtengan las personas naturales, las

- sucesiones indivisas y las sociedades sean nacionales o extranjeras. El ejercicio impositivo

- comprende del 1 de enero al 31 de diciembre. (SRI, s.f.)

- El Impuesto al valor agregado IVA: Es un impuesto que grava al valor de las transferencias locales o importaciones de bienes muebles, en todas sus etapas de comercialización y al valor de los servicios prestados. (SRI, s.f.). Según (Calle) manifiesta que el IVA es Uno de los impuestos que más fondos recauda para el Estado es el IVA, este impuesto tiene su comienzo en el año 1932 la época de la colonia, conocido como la "alcabala" que era un tributo sobre las transacciones comerciales. 
- Las multas tributarias fiscales. Son las sanciones pecuniarias por incumplimientos tributarios, que puede ser por no presentar declaraciones de impuestos, no exhibir la documentación solicitada por el SRI en una auditoría, presentar las declaraciones de manera parcial, con errores o tardíamente, la presentación por fuera del período legal de los anexos de gastos personales. (Andrade \& Cevallos, 2020)

\section{METODOLOGÍA}

La metodología utilizada en el presente trabajo investigativo es de carácter cualitativo y cuantitativo; la primera debido a que se dan parámetros generales del objeto de estudio, en este caso el COVID-19, Impuestos, PIB y cuantitativo por cuanto se presentan cálculos matemáticos y financieros, cuadros analíticos y comparativos para demostrar los principales resultados obtenidos en los últimos periodos económicos, analizando su impacto en la generación de ingresos, por ventas y pro recaudación de impuestos para determinar el impacto generado en la Pandemia en la Industria de Alojamiento y Servicios de Comida. 


\section{BASE DE DATOS}

VAB por Industrias y PIB Ecuador por trimestres año 2011

\begin{tabular}{|c|c|c|c|c|c|c|c|}
\hline \multicolumn{8}{|c|}{2011} \\
\hline Nro. & INDUSTRIA / PERIODO & $\mathbf{T 1}$ & $\mathbf{T} 2$ & $\mathbf{T 3}$ & T4 & Total & $\%$ \\
\hline 1 & Petróleo y minas & $\$ 2,474,753$ & $\$ 2,711,035$ & $\$ 2,471,299$ & $\$ 2,805,769$ & $10,462,856$ & $13.20 \%$ \\
\hline 2 & $\begin{array}{c}\text { Manufactura (excepto refinación de } \\
\text { petróleo) }\end{array}$ & $\$ 2,346,118$ & $\$ 2,412,154$ & $\$ 2,445,560$ & $\$ 2,466,615$ & $\$ 9,670,447$ & $12.20 \%$ \\
\hline 3 & Comercio & $\$ 1,991,860$ & $\$ 2,080,496$ & $\$ 2,139,717$ & $\$ 2,187,743$ & $\$ 8,399,816$ & $10.60 \%$ \\
\hline 4 & Construcción & $\$ 1,853,519$ & $\$ 1,964,192$ & $\$ 2,100,585$ & $\$ 2,188,198$ & $\$ 8,106,494$ & $10.23 \%$ \\
\hline 5 & Agricultura & $\$ 1,623,868$ & $\$ 1,634,715$ & $\$ 1,687,046$ & $\$ 1,756,802$ & $\$ 6,702,431$ & $8.45 \%$ \\
\hline 6 & Enseñanza Servicios sociales y de & $\$ 1,459,734$ & $\$ 1,478,880$ & $\$ 1,487,691$ & $\$ 1,569,541$ & $\$ 5,995,846$ & $7.56 \%$ \\
\hline 7 & Otros Servicios (*) & $\$ 1,231,152$ & $\$ 1,256,126$ & $\$ 1,281,635$ & $\$ 1,294,907$ & $\$ 5,063,820$ & $6.39 \%$ \\
\hline 8 & $\begin{array}{c}\text { Actividades profesionales, técnicas y } \\
\text { administrativas }\end{array}$ & $\$ 1,160,593$ & $\$ 1,234,262$ & $\$ 1,308,491$ & $\$ 1,343,075$ & $\$ 5,046,421$ & $6.37 \%$ \\
\hline 9 & $\begin{array}{c}\text { Administración pública, defensa; planes } \\
\text { de seguridad social obligatoria }\end{array}$ & $\$ 1,147,385$ & $\$ 1,285,401$ & $\$ 1,272,434$ & $\$ 1,308,248$ & $\$ 5,013,468$ & $6.32 \%$ \\
\hline 10 & Transporte & 906,639 & 921,453 & 931,522 & 936,733 & $\$ 3,696,347$ & $4.66 \%$ \\
\hline 11 & Actividades de servicios financieros & 532,828 & 557,038 & 590,019 & $\$ \quad 620,570$ & $\$ 2,300,455$ & $2.90 \%$ \\
\hline 12 & Correo y Comunicaciones & 449,621 & 452,287 & 450,377 & $\$ \quad 459,530$ & $\$ 1,811,815$ & $2.29 \%$ \\
\hline 13 & Alojamiento y servicios de comida & 334,411 & $\$ \quad 352,917$ & 363,506 & $\$ \quad 377,055$ & $\$ 1,427,889$ & $1.80 \%$ \\
\hline 14 & Suministro de electricidad y agua & 202,619 & 229,780 & 246,302 & 248,954 & $\$ \quad 927,655$ & $1.17 \%$ \\
\hline 15 & Refinación de Petróleo & 214,157 & $\$ \quad 171,921$ & 165,334 & $\$ \quad 116,623$ & $\$ \quad 668,035$ & $0.84 \%$ \\
\hline 16 & Pesca (excepto camarón) & 105,595 & 113,064 & 143,351 & 126,107 & 488,117 & $0.62 \%$ \\
\hline 17 & Acuicultura y pesca de camarón & 96,173 & 105,197 & 109,391 & $\$ \quad 110,136$ & $\$ \quad 420,897$ & $0.53 \%$ \\
\hline 18 & Servicio doméstico & 84,724 & 83,278 & 83,459 & 81,945 & $\$ \quad 333,406$ & $0.42 \%$ \\
\hline & Total Valor Agregado Bruto & $\$ 18,215,749$ & $\$ 19,044,196$ & $\$ 19,277,719$ & $\$ 19,998,551$ & $\$ 76,536,215$ & $96.54 \%$ \\
\hline & Otros Elementos del PIB $(* *)$ & 707,206 & $\$ \quad 683,918$ & $\$ \quad 690,751$ & $\$ \quad 658,574$ & $\$ 2,740,449$ & $3.46 \%$ \\
\hline & PIB (***) & $\$ 18,922,955$ & $\$ 19,728,114$ & $\$ 19,968,470$ & $\$ 20,657,125$ & $\$ 79,276,664$ & $100.00 \%$ \\
\hline
\end{tabular}

Anexo: Elaboración propia.

Fuente de datos: (Banco Central del Ecuador, 2020) 
VAB por Industrias y PIB Ecuador por trimestres año 2013

\begin{tabular}{|c|c|c|c|c|c|c|c|}
\hline \multicolumn{8}{|c|}{2013} \\
\hline Nro & INDUSTRIA / PERIODO & T1 & $\mathbf{T} 2$ & $\mathbf{T 3}$ & T4 & Total & $\%$ \\
\hline 1 & $\begin{array}{c}\text { Manufactura (excepto refinación de } \\
\text { petróleo) }\end{array}$ & $2,851,917$ & $2,950,488$ & $3,047,191$ & $3,124,695$ & $11,974,291$ & $12.59 \%$ \\
\hline 2 & Petróleo y minas & $2,990,265$ & $2,892,812$ & $3,091,849$ & $2,876,240$ & $11,851,166$ & $12.46 \%$ \\
\hline 3 & Construcción & $2,448,769$ & $2,483,745$ & $2,529,185$ & $2,550,964$ & $10,012,663$ & $10.53 \%$ \\
\hline 4 & Comercio & $2,416,809$ & $2,475,767$ & $2,530,737$ & $2,553,333$ & $9,976,646$ & $10.49 \%$ \\
\hline 5 & Enseñanza Servicios sociales y de salud & $1,811,667$ & $1,870,645$ & $1,894,100$ & $1,937,034$ & $7,513,446$ & $7.90 \%$ \\
\hline 6 & Agricultura & $1,740,048$ & $1,777,310$ & $1,816,142$ & $1,897,202$ & $7,230,702$ & $7.60 \%$ \\
\hline 7 & $\begin{array}{c}\text { Actividades profesionales, técnicas y } \\
\text { administrativas }\end{array}$ & $1,555,030$ & $1,612,390$ & $1,662,416$ & $1,719,941$ & $6,549,777$ & $6.89 \%$ \\
\hline 8 & $\begin{array}{l}\text { Administración pública, defensa; } \\
\text { planes de seguridad social obligatoria }\end{array}$ & $1,471,983$ & $1,500,765$ & $1,538,264$ & $1,539,900$ & $6,050,912$ & $6.36 \%$ \\
\hline 9 & Otros Servicios $(*)$ & $1,367,612$ & $1,391,931$ & $1,406,182$ & $1,426,850$ & $5,592,575$ & $5.88 \%$ \\
\hline 10 & Transporte & $1,033,022$ & $1,062,576$ & $1,087,927$ & $1,116,037$ & $4,299,562$ & $4.52 \%$ \\
\hline 11 & Correo y Comunicaciones & 494,802 & 501,882 & 508,242 & 516,559 & $2,021,485$ & $2.12 \%$ \\
\hline 12 & Actividades de servicios financieros & 646,04 & 636,564 & 643,431 & 664,518 & $1,944,513$ & $2.04 \%$ \\
\hline 13 & Alojamiento y servicios de comida & 446,433 & 463,333 & 477,43 & 490,366 & $1,400,132$ & $1.47 \%$ \\
\hline 14 & Suministro de electricidad y agua & 279,23 & 246,885 & 284,557 & 254,856 & 786,298 & $0.83 \%$ \\
\hline 15 & Pesca (excepto camarón) & 129,366 & 156,811 & 161,915 & 147,813 & 595,905 & $0.63 \%$ \\
\hline 16 & Acuicultura y pesca de camarón & 114,691 & 128,235 & 130,314 & 142,399 & 515,639 & $0.54 \%$ \\
\hline 17 & Refinación de Petróleo & 50,212 & 48,666 & 162,064 & 172,395 & 433,337 & $0.46 \%$ \\
\hline \multirow[t]{4}{*}{18} & Servicio doméstico & 91,115 & 94,863 & 96,986 & 99,149 & 382,113 & $0.40 \%$ \\
\hline & Total Valor Agregado Bruto & $21,939,011$ & $22,295,668$ & $23,068,932$ & $23,230,251$ & $\mathbf{9 0 , 5 3 3 , 8 6 2}$ & $95.17 \%$ \\
\hline & Otros Elementos del PIB (**) & $1,080,775$ & $1,145,656$ & $1,169,644$ & $1,199,722$ & $4,595,797$ & $4.83 \%$ \\
\hline & PIB $(* * *)$ & $23,019,786$ & $23,441,324$ & $24,238,576$ & $24,429,973$ & $95,129,659$ & $100.00 \%$ \\
\hline
\end{tabular}

Anexo: Elaboración propia.

Fuente de datos: (Banco Central del Ecuador, 2020) 
VAB por Industrias y PIB Ecuador por trimestres año 2020

\begin{tabular}{|c|c|c|c|c|c|c|c|}
\hline \multicolumn{8}{|c|}{2020} \\
\hline Nro. & INDUSTRIA / PERIODO & $\mathbf{T 1}$ & $\mathbf{T 2}$ & T3 & T4 & Total & $\%$ \\
\hline 1 & $\begin{array}{c}\text { Manufactura (excepto refinación de } \\
\text { petróleo) }\end{array}$ & $3,721,452$ & $3,439,274$ & $3,452,486$ & $3,448,675$ & $14,061,887$ & $14.23 \%$ \\
\hline 2 & Construcción & $2,820,583$ & $2,520,966$ & $2,560,983$ & $2,568,857$ & $10,471,389$ & $10.60 \%$ \\
\hline 3 & Comercio & $2,444,313$ & $2,227,633$ & $2,347,684$ & $2,413,200$ & $9,432,830$ & $9.55 \%$ \\
\hline 4 & Enseñanza Servicios sociales y de salud & $2,382,595$ & $2,174,632$ & $2,190,501$ & $2,158,513$ & $8,906,241$ & $9.01 \%$ \\
\hline 5 & Agricultura & $2,229,189$ & $2,073,968$ & $2,088,149$ & $2,116,274$ & $8,507,580$ & $8.61 \%$ \\
\hline 6 & $\begin{array}{c}\text { Actividades profesionales, técnicas y } \\
\text { administrativas }\end{array}$ & $1,993,244$ & $1,769,379$ & $1,838,559$ & $1,944,112$ & $7,545,294$ & $7.64 \%$ \\
\hline 7 & $\begin{array}{c}\text { Administración pública, defensa; planes } \\
\text { de seguridad social obligatoria }\end{array}$ & $1,740,176$ & $1,628,897$ & $1,626,622$ & $1,649,878$ & $6,645,573$ & $6.73 \%$ \\
\hline 8 & Otros Servicios (*) & $1,574,356$ & $1,507,337$ & $1,521,734$ & $1,499,263$ & $6,102,690$ & $6.18 \%$ \\
\hline 9 & Transporte & $1,431,955$ & $1,132,899$ & $1,121,256$ & $1,191,294$ & $4,877,404$ & $4.94 \%$ \\
\hline 10 & Petróleo y minas & $1,240,977$ & 763,857 & $1,014,048$ & $1,050,509$ & $4,069,391$ & $4.12 \%$ \\
\hline 11 & Actividades de servicios financieros & 963,04 & 899,904 & 955,603 & $1,058,405$ & $2,913,912$ & $2.95 \%$ \\
\hline 12 & Alojamiento y servicios de comida & 596,764 & 508,785 & 508,227 & 525,354 & $2,139,130$ & $2.16 \%$ \\
\hline 13 & Correo y Comunicaciones & 485,63 & 456,686 & 477,775 & 487,567 & $1,422,028$ & $1.44 \%$ \\
\hline 14 & Refinación de Petróleo & 294,172 & 265,204 & 366,807 & 396,774 & $1,322,957$ & $1.34 \%$ \\
\hline 15 & Suministro de electricidad y agua & 467,909 & 455,638 & 406,08 & 367,763 & $1,291,310$ & $1.31 \%$ \\
\hline 16 & Acuicultura y pesca de camarón & 173,375 & 173,891 & 170,111 & 171,93 & 517,377 & $0.52 \%$ \\
\hline 17 & Pesca (excepto camarón) & 121,886 & 122,058 & 124,955 & 120,662 & 489,561 & $0.50 \%$ \\
\hline 18 & Servicio doméstico & 146,212 & 143,363 & 146,49 & 137,226 & 426,801 & $0.43 \%$ \\
\hline & Total Valor Agregado Bruto & $24,827,828$ & $22,264,371$ & $22,918,070$ & $23,306,25$ & $70,010,269$ & $70.85 \%$ \\
\hline & Otros Elementos del PIB (**) & $1,423,006$ & $1,280,433$ & $1,413,480$ & $1,374,566$ & $5,491,485$ & $5.56 \%$ \\
\hline & PIB (***) & $26,250,834$ & $23,544,804$ & $24,331,550$ & $24,680,822$ & $98,808,010$ & $100.00 \%$ \\
\hline
\end{tabular}

Anexo: Elaboración propia.

Fuente de datos: (Banco Central del Ecuador, 2020)

\section{Recaudación Nacional vs. Recaudación de la Industria de Alojamiento y Servicios de Comida}

\begin{tabular}{ccccccc}
\hline \multicolumn{6}{c}{ Recaudación Tributaria Nacional y de la Industria de Alojamiento y Servicios de Comida } \\
\hline Año & Nacional & $\begin{array}{c}\text { \% de } \\
\text { variación }\end{array}$ & Industria & $\begin{array}{c}\text { \% de } \\
\text { variación }\end{array}$ & $\begin{array}{c}\text { \% de } \\
\text { participación }\end{array}$ \\
\hline 2018 & $\$$ & $14,450,000,000$ & & $\$ 163,328,317$ & & $1.13 \%$ \\
2019 & $\$$ & $14,872,611,000$ & $2.92 \%$ & $\$ 167,150,161$ & $2.34 \%$ & $1.12 \%$ \\
2020 & $\$$ & $11,526,978,000$ & $-22.50 \%$ & $\$ 119,462,741$ & $-28.53 \%$ & $1.04 \%$ \\
\hline Total & $\$$ & $\mathbf{4 0 , 8 4 9 , 5 8 9 , 0 0 0}$ & & $\mathbf{4 4 9 , 9 4 1 , 2 1 9}$ & & $\mathbf{1 . 1 0 \%}$ \\
\hline
\end{tabular}

Tabla: Elaboración propia.

Fuente de datos: (SRI, 2020) 
Resumen General de los Sectores de Alojamiento y Servicios de Comida del 2016 al 2020

\begin{tabular}{|c|c|c|c|c|c|c|c|c|}
\hline \multicolumn{9}{|c|}{ RESUMEN GENERAL DE ALOJAMIENTO Y SERVICIOS DE COMIDA 2016 -2020 } \\
\hline \multicolumn{5}{|c|}{ Alojamiento } & \multicolumn{4}{|c|}{ Servicios de Comida } \\
\hline Año & $\begin{array}{c}\text { Establecimientos } \\
\text { Registrados }\end{array}$ & $\begin{array}{c}\% \text { de } \\
\text { variación }\end{array}$ & Empleos & $\begin{array}{c}\% \text { de } \\
\text { variación }\end{array}$ & $\begin{array}{c}\text { Establecimientos } \\
\text { Registrados }\end{array}$ & $\begin{array}{c}\% \text { de } \\
\text { variación }\end{array}$ & Empleos & $\begin{array}{c}\% \text { de } \\
\text { variación }\end{array}$ \\
\hline 2016 & 5,488 & & & & & & 85,653 & \\
\hline 2017 & & -5.6 & 34,306 & -3.3 & & & 88,263 & $3.05 \%$ \\
\hline 2018 & 3,658 & $-29.34 \%$ & 27,861 & $-18.79 \%$ & & -4 . & 88,604 & $0.39 \%$ \\
\hline 2019 & 4,153 & $13.53 \%$ & 28,554 & $2.49 \%$ & 17,225 & $-0.05 \%$ & 89,809 & $1.36 \%$ \\
\hline 2020 & 4,211 & $1.40 \%$ & 28,030 & $-1.84 \%$ & 16,443 & $-4.54 \%$ & 88,839 & $-1.08 \%$ \\
\hline
\end{tabular}

Tabla: Elaboración propia.

Fuente de datos: (Ministerio de Turismo, 2020)

Ventas Totales de todas las Industrias vs. Ventas de la Industria de Alojamiento y Servicio de comida desde el 2011 al 2020

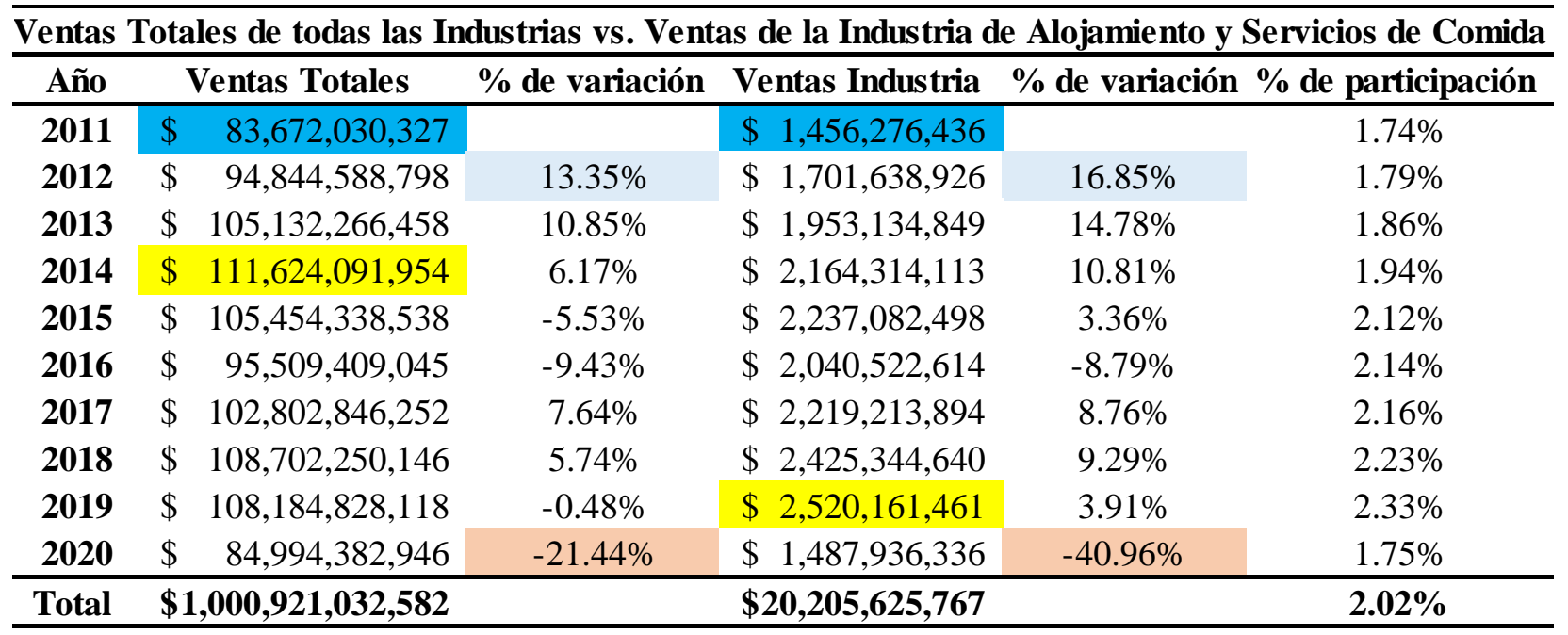

Tabla: Elaboración propia.

Fuente de datos: (SAIKU, SRI, 2021)

\section{RESULTADOS}

\section{PIB-VAB}

Para esta investigación se ha tomado en consideración 11 períodos desde el 2010 al 2020 que permita corroborar el impacto generado por la Pandemia COVID-19 a nivel productivo en el país y poderlo comparar con el efecto obtenido en el 2020, fenómeno económico que ha golpeado duramente las cifras macroeconómicas y que durante los últimos años no se ha podido evidenciar algo similar a pesar de haber pasado por duras y difíciles recesiones económicas pero ninguna similar a la del 2020. 
A continuación, se presenta la comparación, variación y participación del PIB del país y el VAB de la Industria de Alojamiento y Servicios de Comida 2010 - 2020.

Tabla 1. PIB Nacional y VAB de la Industria de Alojamiento y Servicios de Comida 2010 $-2020$

\begin{tabular}{ccccccc}
\hline \multicolumn{5}{c}{ PIB Nacional y VAB de la Industria de Alojamiento y Servicios de Comida } \\
\hline \multirow{2}{*}{ Año } & PIB Ecuador & $\begin{array}{c}\text { \% de } \\
\text { variación }\end{array}$ & VAB Industria & $\begin{array}{c}\text { \% de } \\
\text { variación }\end{array}$ & $\begin{array}{c}\text { \% de } \\
\text { participación }\end{array}$ \\
\hline $\mathbf{2 0 1 0}$ & $\$ 69,555,367,000$ & $11.25 \%$ & $\$ 1,312,445,000$ & $5.30 \%$ & $1.89 \%$ \\
$\mathbf{2 0 1 1}$ & $\$ 79,276,664,000$ & $13.98 \%$ & $\$ 1,427,889,000$ & $8.80 \%$ & $1.80 \%$ \\
$\mathbf{2 0 1 2}$ & $\$ 87,924,544,000$ & $10.91 \%$ & $\$ 1,631,804,000$ & $14.28 \%$ & $1.86 \%$ \\
$\mathbf{2 0 1 3}$ & $\$ 95,129,659,000$ & $8.19 \%$ & $\$ 1,877,562,000$ & $15.06 \%$ & $1.97 \%$ \\
$\mathbf{2 0 1 4}$ & $\$ 101,726,331,000$ & $6.93 \%$ & $\$ 2,054,398,000$ & $9.42 \%$ & $2.02 \%$ \\
$\mathbf{2 0 1 5}$ & $\$ 99,290,381,000$ & $-2.39 \%$ & $\$ 2,083,056,000$ & $1.39 \%$ & $2.10 \%$ \\
$\mathbf{2 0 1 6}$ & $\$ 99,937,696,000$ & $0.65 \%$ & $\$ 2,123,199,000$ & $1.93 \%$ & $2.12 \%$ \\
$\mathbf{2 0 1 7}$ & $\$ 104,295,862,000$ & $4.36 \%$ & $\$ 2,225,384,000$ & $4.81 \%$ & $2.13 \%$ \\
$\mathbf{2 0 1 8}$ & $\$ 107,562,008,000$ & $3.13 \%$ & $\$ 2,314,342,000$ & $4.00 \%$ & $2.15 \%$ \\
$\mathbf{2 0 1 9}$ & $\$ 107,436,000,000$ & $-0.12 \%$ & $\$ 2,422,591,000$ & $4.68 \%$ & $2.25 \%$ \\
$\mathbf{2 0 2 0}$ & $\$ 98,808,010,000$ & $-8.03 \%$ & $\$ 2,139,130,000$ & $-11.70 \%$ & $2.16 \%$ \\
\hline
\end{tabular}

Tabla: Elaboración propia.

Fuente de datos: (Banco Central del Ecuador, 2020)

Gráfica 1. Evolución del PIB Ecuador vs. el VAB de la Industria de Alojamiento y Servicios de Comida 2010 - 2020.

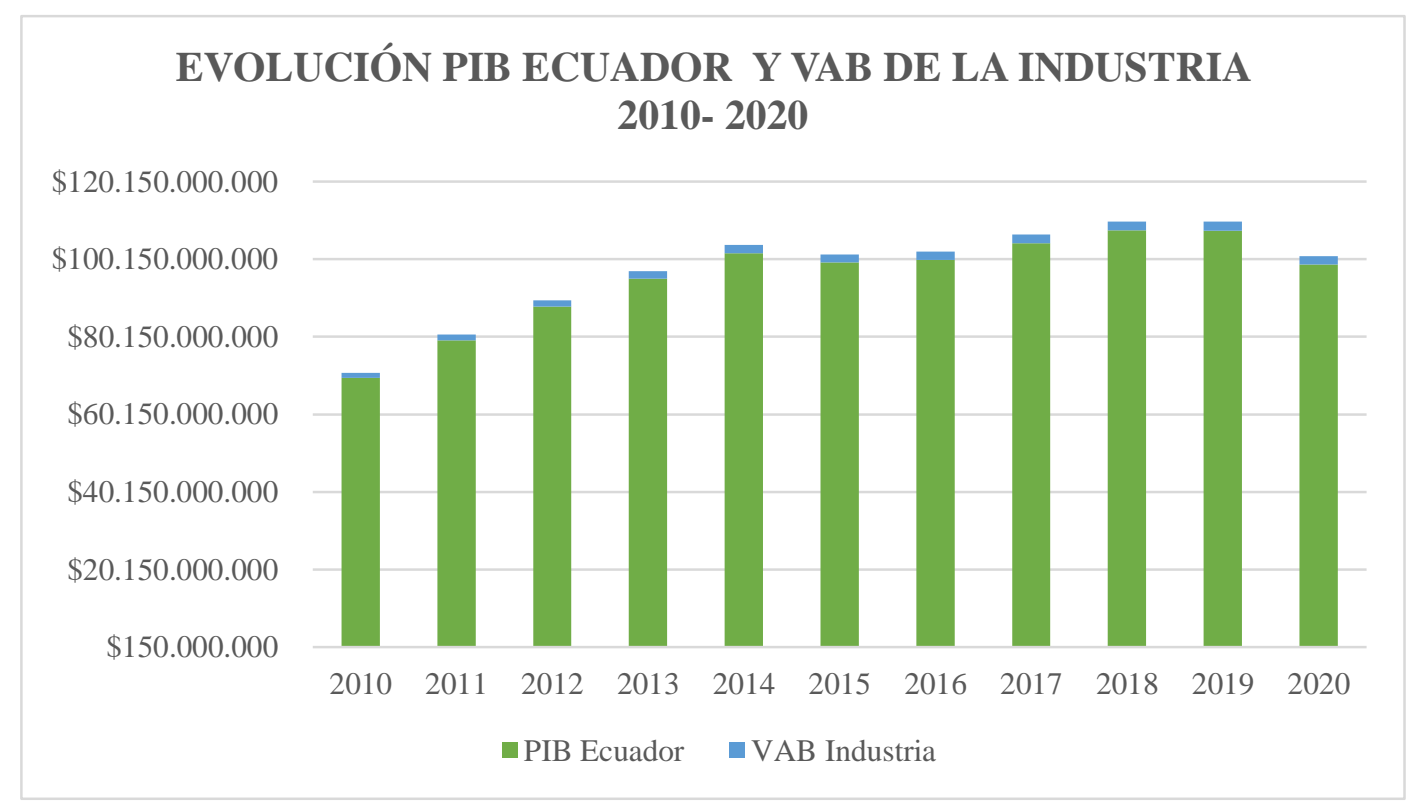

Gráfica: Elaboración propia.

Fuente de datos: (Banco Central del Ecuador, 2020) 
Al observar la tabla \#1 y la gráfica \#1 se concluye que en el año 2011 se obtuvo el mayor incremento de PIB del país con el 13.98\% y en el 2018 fue el año con mayor PIB donde se obtuvo $\$ 107,562,008,000$; mientras que en el 2020 es el año en el cual decrece con mayor impacto en $-8.03 \%$. Es importante señalar que el auge del PIB en el 2011 fue por la contribución de cinco industrias que aportaron en total con el 54.67\% y son Petróleo y Minas, Manufactura (excepto refinación de petróleo), Comercio, Construcción y Agricultura (Anexo 1), mientras que en el 2020 los sectores que más aportaron al PIB con el 52\% fueron Manufactura (excepto refinación de petróleo), Construcción, Comercio, Enseñanza, Servicios Sociales y de Salud y Agricultura (Anexo 3) dándose a notar que la Industria de Manufactura es una Industria muy importante dentro del PIB ya que en estos años ha estado entre el primer y segundo lugar entre las Industrias que más aportan.

De igual forma en el VAB (Valor Agregado Bruto) de la Industria de Alojamiento y Servicios de Comida el mayor crecimiento en los 11 años de análisis es en el 2013 con el $15.06 \%$ mientras que el año 2020 tuvo el mayor decrecimiento del $-11.70 \%$ como resultado del cierre de fronteras por la emergencia sanitaria que incidió en una menor demanda de hoteles, restaurantes y servicios relacionados, no obstante, aunque exista este decrecimiento arraigado a las consecuencias del COVID - 19, 2020 fue el segundo año con mayor aporte al PIB del $2.16 \%$ en los últimos 11 años. La Industria de Alojamiento y Servicios de Comida pasó de ocupar el treceavo puesto de 18 Industrias en el año 2013 con un aporte del $1.47 \%$ al doceavo puesto en el año 2020 con el $2.16 \%$ de participación en el PIB del país (Anexo 2). (Banco Central del Ecuador, 2020)

El sector de Alojamiento es el más golpeado en sus resultados, seguido por Servicios de Comida. Esta conclusión se basa en el análisis del comportamiento de Recaudación Tributaria que se analizará a continuación.

\section{Recaudación de Impuestos}

Para analizar la recaudación de impuestos de la Industria de Alojamiento y Servicios de Comida, el Servicio de Rentas Internas del Ecuador (SRI) lo ha desglosado en Sector de Alojamiento y Sector de Servicios de Comida a partir del 2018 en adelante.

De acuerdo al Servicio de Rentas Internas (SRI) La recaudación de impuestos en el país está conformada por:

1. Impuesto a la Renta

2. Impuesto al Valor Agregado (IVA) 
3. Impuesto a los consumos especiales (ICE)

4. Impuesto fomento ambiental

5. Impuesto a los vehículos motorizados

6. Impuesto a la salida de divisas

7. Impuesto Activos en el exterior

8. RISE

9. Regalías, patentes y utilidades de conservación minera

10. Contribución para la atención integral del cáncer

11. Contribución única y Temporal

12. Intereses por Mora tributaria

13. Multas Tributarias Fiscales

14. Otros Ingresos

En diciembre del 2020 la autoridad tributaria indicó que solo en este mes se recaudó USD 1.068 millones, lo que equivale a un incremento de USD 34 millones y un crecimiento del $3,3 \%$ con respecto a diciembre de 2019 .

La recaudación por concepto del impuesto al valor agregado (IVA), durante el período enero - diciembre 2020, alcanzó los USD 5506 millones. En tanto que la recaudación mensual (diciembre de 2020), por este mismo concepto, fue de USD 550 millones, lo que significó un crecimiento del 4,2\% en relación al mismo mes de 2019.

Por impuesto a la renta (IR), durante el 2020, se recaudaron USD 4406 millones, mientras que, únicamente en el último mes de ese año, se registró una recaudación de USD 300 millones, es decir, 9,3\% de crecimiento con relación a diciembre de 2019.

Con respecto al Impuesto a los Consumos Especiales (ICE), se recaudaron USD 740 millones durante todo el año pasado. En diciembre de 2020, por concepto de este impuesto se recaudaron USD 76 millones, es decir, 4,8\% de crecimiento en relación al mismo mes de 2019. (Orozco, 2021)

A continuación, se presenta un análisis de la Recaudación Tributaria generada en los últimos tres años correspondiente a la Industria de Alojamiento y Servicios de Comida: 
Tabla 2. Recaudación Nacional vs. Recaudación de la Industria de Alojamiento y Servicios de Comida

\begin{tabular}{ccccccc}
\hline \multicolumn{6}{c}{ Recaudación Tributaria Nacional y de la Industria de Alojamiento y Se rvicios de Comida } \\
\hline \multirow{2}{*}{ Año } & Nacional & $\begin{array}{c}\text { \% de } \\
\text { variación }\end{array}$ & Industria & $\begin{array}{c}\text { \% de } \\
\text { variación }\end{array}$ & $\begin{array}{c}\text { \% de } \\
\text { participación }\end{array}$ \\
\hline 2018 & $\$$ & $14,450,000,000$ & & $\$ 163,328,317$ & & $1.13 \%$ \\
2019 & $\$$ & $14,872,611,000$ & $2.92 \%$ & $\$ 167,150,161$ & $2.34 \%$ & $1.12 \%$ \\
2020 & $\$$ & $11,526,978,000$ & $-22.50 \%$ & $\$ 119,462,741$ & $-28.53 \%$ & $1.04 \%$ \\
\hline Total & $\$$ & $\mathbf{4 0 , 8 4 9 , 5 8 9 , 0 0 0}$ & & $\mathbf{\$ 4 4 9 , 9 4 1 , 2 1 9}$ & & $\mathbf{1 . 1 0 \%}$ \\
\hline
\end{tabular}

Tabla: Elaboración propia.

Fuente de datos: (SRI, 2020)

Gráfica 2. Evolución de la Recaudación Tributaria Nacional vs. de la Industria de Alojamiento y Servicios de Comida 2018 - 2020

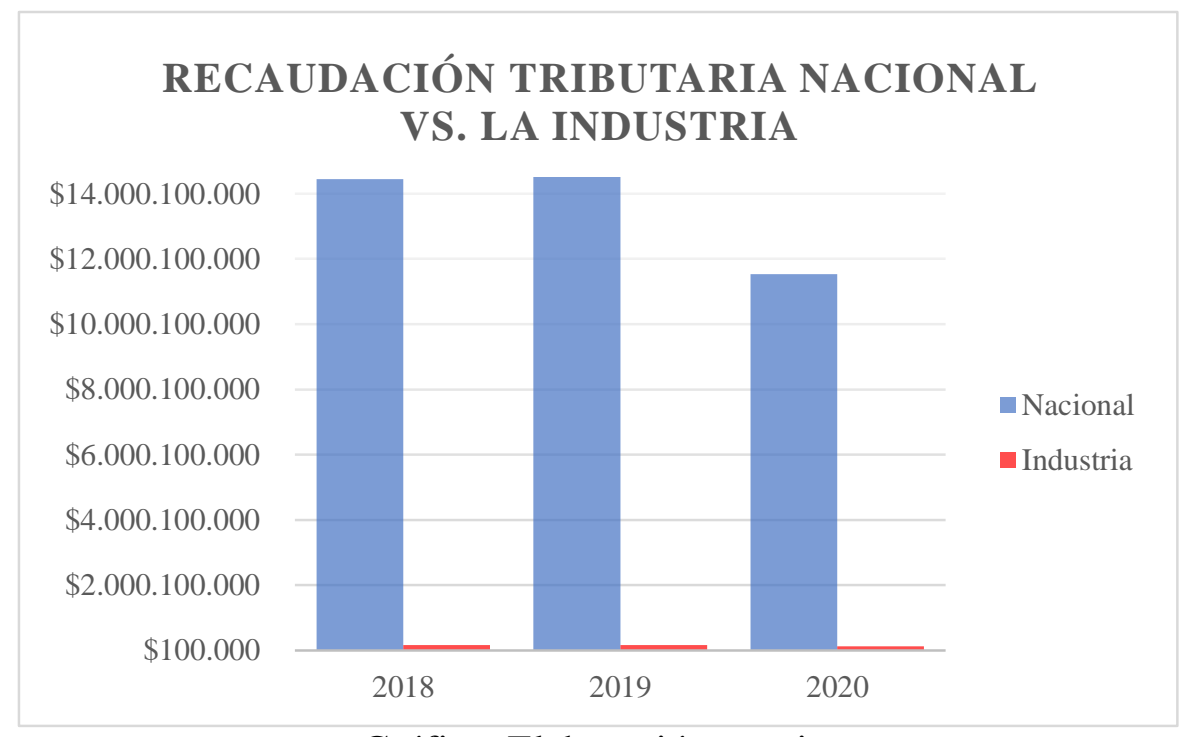

Gráfica: Elaboración propia.

Fuente de datos: (SRI, 2020)

Como se puede observar en la tabla y gráfica \#2, la recaudación tributaria de los años 2018 y 2019 superó los 14 millones, sin embargo, para el año 2020 hubo un decrecimiento del $-22.50 \%$ poniendo en evidencia los efectos que tuvo la pandemia en la economía del país. A su vez, si se compara la recaudación nacional vs. la Industria de Alojamiento y Servicio de Comidas se puede conocer que la participación que tuvo ésta en la recaudación total fue en promedio del $1.10 \%$ y que de igual manera la Industria para el año 2020 se vio afectada con un $-28.53 \%$ menos que el año pasado. 
Análisis comparativo del Sector de Alojamiento y Servicios de Comida

Tabla 3: Recaudación Total de la Industria de Alojamiento y Servicios de Comida vs el Sector de Alojamiento y el Sector de Servicios de Comida.

\begin{tabular}{|c|c|c|c|c|c|c|c|}
\hline \multicolumn{8}{|c|}{ ria de la Industria y de los Sectores de Alojamiento y Servicio de Comidas } \\
\hline Año & Ind & Alo & $\begin{array}{c}\% \text { de } \\
\text { participación }\end{array}$ & $\begin{array}{c}\% \text { de } \\
\text { variación }\end{array}$ & $\begin{array}{c}\text { Servicio de } \\
\text { Comidas }\end{array}$ & $\begin{array}{c}\% \text { de } \\
\text { participación }\end{array}$ & $\begin{array}{c}\% \text { de } \\
\text { variación }\end{array}$ \\
\hline 201 & 7 & & & & & & \\
\hline 2019 & & & & & & & \\
\hline 2020 & $\$ 119,462,741$ & $\$ 17,670,158$ & $14.79 \%$ & $-46.05 \%$ & $\$ 101$ & $85.21 \%$ & $-24.26 \%$ \\
\hline otal & $\$ 449,941,219$ & $\$ 81,378,489$ & $18.09 \%$ & & $\$ 368,562,730$ & $81.91 \%$ & \\
\hline
\end{tabular}

Tabla: Elaboración propia.

Fuente de datos: (SRI, 2020)

Al observar la tabla \#3 junto a la recaudación tributaria por cada sector, se puede concluir en primer lugar que, el sector de Servicio de Comidas es un sector estratégico con alta relevancia para la Industria debido a que desde el año 2018 al 2020 ha tenido una participación en total del $81.91 \%$ a comparación de Alojamiento que representó apenas el 18.09\%. En segundo lugar, se puede evidenciar que durante el año 2020 en un escenario donde el Covid-19 amenazaba la estabilidad de los emprendimientos, el sector de Servicio de Comidas ha sido el menos afectado a comparación de Alojamiento, de esta manera el sector de Servicio de Comidas tuvo un decrecimiento del - 24.26\% y Alojamiento del $46.05 \%$.

Gráfica 3. Recaudación Tributaria de Alojamiento vs. Servicios de Comidas 2018-2020

\section{EVOLUCIÓN RECAUDACIÓN TRIBUTARIA DE ALOJAMIENTO Y SERVICIOS DE COMIDA 2018 - 2020}

$\$ 155.000 .000$

$\$ 135.000 .000$

$\$ 115.000 .000$

$\$ 95.000 .000$

$\$ 75.000 .000$ Alojamiento

$\$ 55.000 .000$

$\longrightarrow$ Servicio de Comidas

$\$ 35.000 .000$

$\$ 15.000 .000$
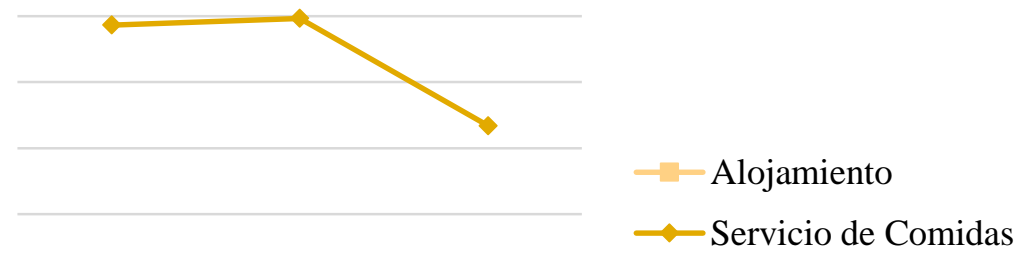

\$15.000.000

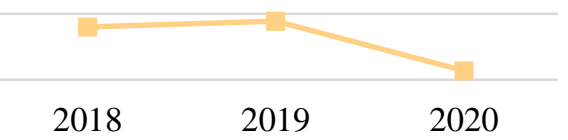

Gráfica: Elaboración propia.

Fuente de datos: (SRI, 2020) 
Gráfica 4. Participación porcentual de Alojamiento vs. Servicios de Comida desde el 2018 al 2020

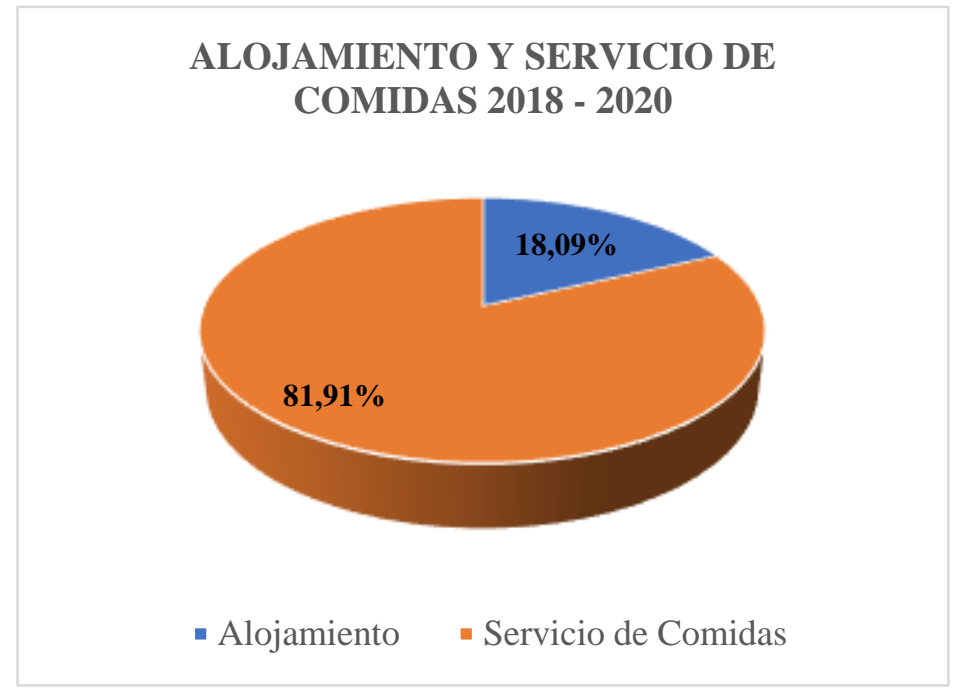

Gráfica: Elaboración propia.

Fuente de datos: (SRI, 2020)

\section{Establecimientos Registrados y Empleos generados por la Industria de Alojamiento}

\section{y Servicios de Comidas 2016 - 2020}

La emergencia sanitaria ha afectado en gran escala al sector turístico especialmente a la Industria de Alojamiento y Servicios de Comida dado que las actividades involucradas en esta cadena productiva estuvieron paralizadas durante inicios de la pandemia debido a que el teletrabajo no era una opción para estas actividades ya que requieren contacto personal y así como también se vieron limitados por cientos de restricciones establecidas por el COE. Sin embargo, según datos publicados del Ministerio de Turismo se pudo conocer que el efecto de la pandemia al finalizar el año 2020 no fueron de gran impacto en lo que se refiere a número de empleos y establecimientos registrados.

A continuación, se presenta un resumen general del período 2016 al 2020 de los sectores de Alojamiento y Servicios de Comida.

Tabla 4. Resumen General de los Sectores de Alojamiento y Servicios de Comida del 2016 al 2020

\begin{tabular}{|c|c|c|c|c|c|c|c|c|}
\hline \multicolumn{9}{|c|}{ RESUMEN GENERAL DE ALOJAMIENTO Y SERVICIOS DE COMIDA $2016-2020$} \\
\hline & \multicolumn{4}{|c|}{ Alojamiento } & \multicolumn{4}{|c|}{ Servicios de Comida } \\
\hline Año & $\begin{array}{c}\text { Establecimientos } \\
\text { Registrados }\end{array}$ & $\begin{array}{c}\% \text { de } \\
\text { variación }\end{array}$ & Empleos & $\begin{array}{c}\% \text { de } \\
\text { variación }\end{array}$ & $\begin{array}{c}\text { Establecimientos } \\
\text { Registrados }\end{array}$ & $\begin{array}{c}\% \text { de } \\
\text { variación }\end{array}$ & Empleos & $\begin{array}{c}\% \text { de } \\
\text { variación }\end{array}$ \\
\hline 2016 & 5,488 & & 35 & & 17 , & & 85,653 & \\
\hline 2017 & 5,177 & $-5.67 \%$ & 34,306 & $-3.30 \%$ & 17,965 & $3.69 \%$ & 88,263 & $3.05 \%$ \\
\hline 2018 & 3,658 & $-29.34 \%$ & 27,861 & $-18.79 \%$ & 17,233 & $-4.07 \%$ & 88,604 & $0.39 \%$ \\
\hline 2019 & 4,153 & $13.53 \%$ & 28,554 & $2.49 \%$ & 17,225 & $-0.05 \%$ & 89,809 & $1.36 \%$ \\
\hline 2020 & 4,211 & $1.40 \%$ & 28,030 & $-1.84 \%$ & 16,443 & $-4.54 \%$ & 88,839 & $-1.08 \%$ \\
\hline
\end{tabular}

Tabla: Elaboración propia.

Fuente de datos: (Ministerio de Turismo. 2020) 
Gráfica 5. Establecimientos registrados y empleos de Alojamiento 2016 - 2020

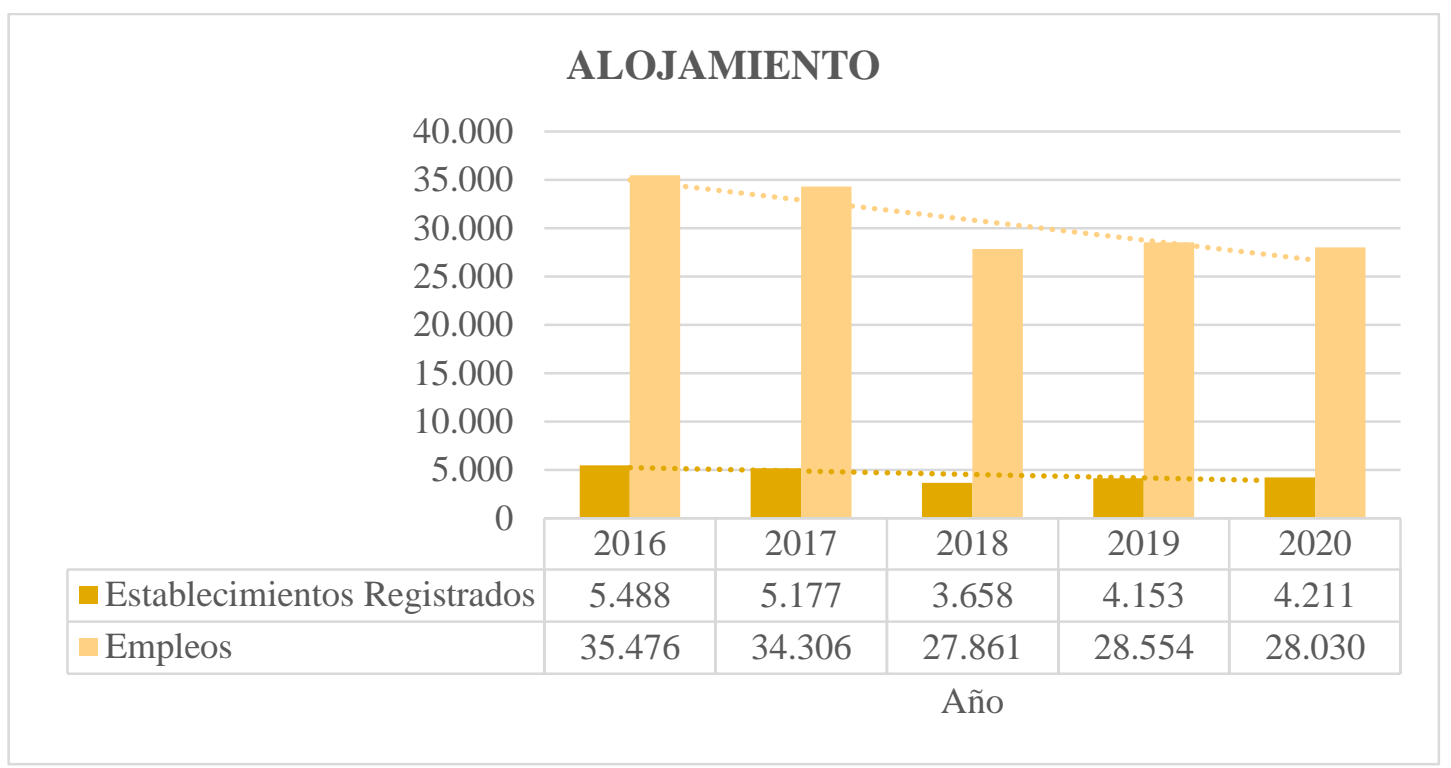

Gráfica: Elaboración propia.

Fuente de datos: (Ministerio de Turismo, 2020)

Gráfica 6. Establecimientos registrados y empleos de Servicios de Comida 2016 - 2020

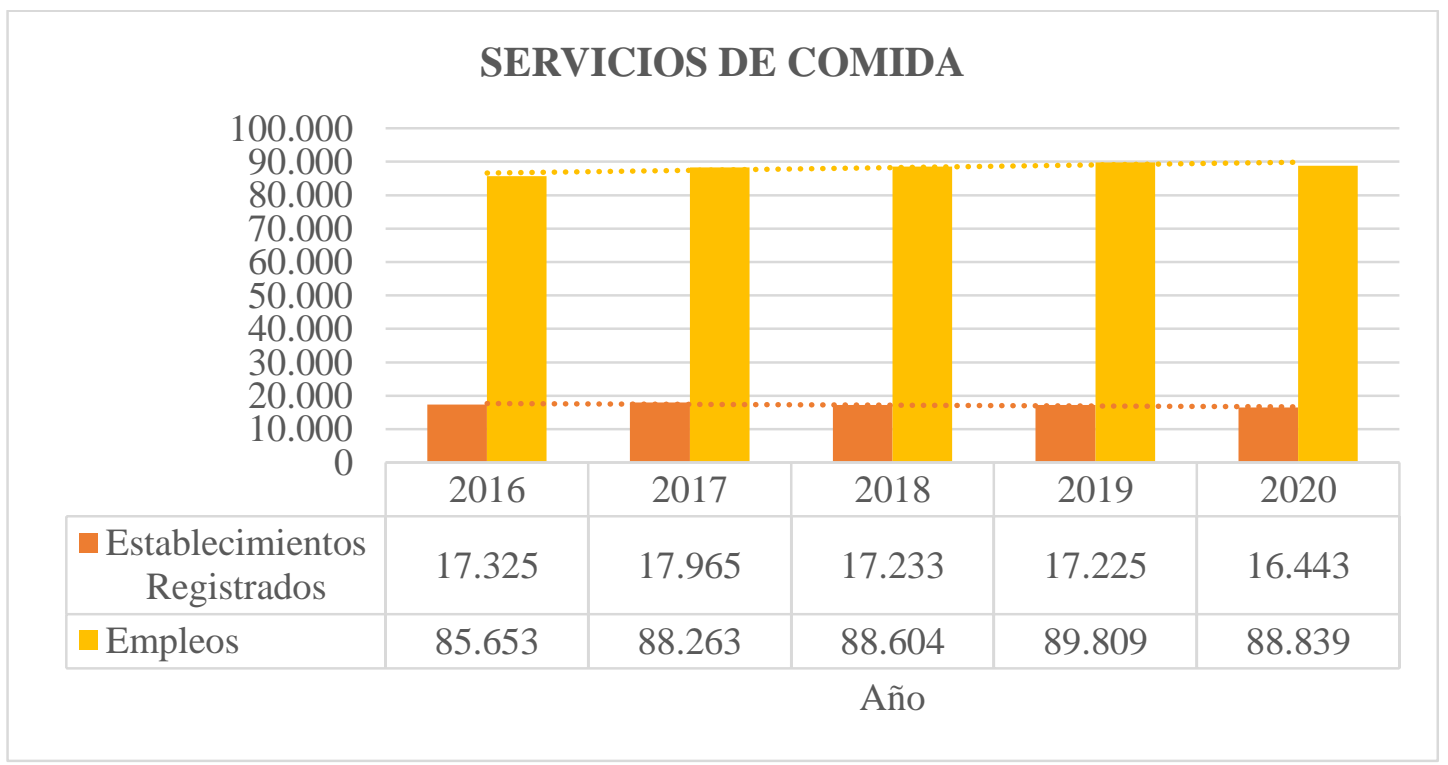

Gráfica: Elaboración propia.

Fuente de datos: (Ministerio de Turismo, 2020)

Como se puede observar en la tabla y las gráficas existe una correlación con los establecimientos registrados vs. los empleos generados. Para Alojamientos, la tendencia desde el año 2016 ha ido decreciendo, teniendo al año 2018 con la menor variación y el año 2019 con el mayor porcentaje de crecimiento. En la emergencia sanitaria a pesar de 
que los establecimientos tuvieron que dejar de operar, los datos demuestran que terminaron el año 2020 con índices óptimos en cuanto a estas dos variables. Sin embargo, es importante considerar que el número de establecimientos registrados no demuestran la realidad de los negocios a lo que refiere a su liquidez para cumplir con sus obligaciones e incluso para cubrir sus gastos operativos. Asimismo, el número de empleos no reflejan las condiciones reales de los trabajadores en tiempos de pandemia como, por ejemplo, contratos y salarios.

En la gráfica \#6 del sector de Servicios de Comida se puede observar una línea de tendencia sostenida dado que sus datos se han mantenido con variaciones mínimas. Es así como el año 2017 tuvo el mayor porcentaje de variación y el año 2020 el menor crecimiento a comparación del año pasado.

No obstante, estos datos no demuestran la realidad que vivieron las PYMES, grandes empresas y trabajadores durante el año 2020.

Mediante la recolección de datos de SAIKU, SRI se pudo conocer las ventas generadas desde el año 2011 al 2020 de las actividades económicas que conforman la Industria de Alojamiento y Servicio de Comidas.

A continuación, se presenta los códigos y la descripción de las 14 actividades económicas clasificadas entre Alojamiento y Servicios de Comida. 
Tabla 5. Nomenclatura de las Actividades Económicas de la Industria de Alojamiento y Servicios de Comida según el CIIU 4.0
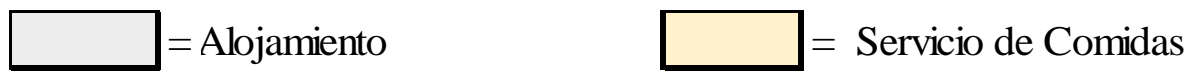

\begin{tabular}{ll}
\hline Actividades Económicas de la Industria de Alojamiento y Servicio de Comidas \\
\hline I5510.01 & $\begin{array}{l}\text { Servicios de alojamiento prestados por hoteles, hoteles de suites, apart hoteles, complejos turísticos, } \\
\text { hosterías. }\end{array}$
\end{tabular}

I5510.02 Servicios de alojamiento prestados por moteles.

I5510.09 Otros servicios de alojamientos por corto tiempo: casas de huéspedes; cabañas, chalets, cabañas con servicio de mantenimiento y limpieza, hostales juveniles y refugios de montaña.

Provisión de alamiento en campamentos, parques para caravanas, campamentos recreativos y

I5520.00 campamentos de caza y de pesca para estancias cortas. Espacio e instalaciones para vehículos de recreo. Se incluye refugios o simples instalaciones de acampada para plantar tiendas o pernoctar en sacos de dormir.

I5590.01 Servicios de residencias de estudiantes, dormitorios escolares, albergues para trabajadores, casas de huéspedes e internados.

I5610.01 Restaurantes, cevicherías, picanterías, cafeterías, etcétera, incluido comida para llevar.

I5610.02 Restaurantes de comida rápida, puestos de refrigerio y establecimientos que ofrecen comida para llevar, reparto de pizza, etcétera; heladerías, fuentes de soda, etcétera.

Preparación y suministro de comidas para su consumo inmediato de manera ambulante, mediante

I5610.03 un vehículo motorizado o carro no motorizado, venededores de helados en carros móviles, carritos ambulantes de comida incluye la preparación de comida en puestos de mercados.

I5610.04 Servicios de restaurantes y bares en conexión con transporte cuando son proporcionadas por unidades independientes: bares del aeropuerto, bares terminales terrestres, etcétera.

Servicio de comidias basado en acuerdos contractuales con el cliente para un evento (banquetes,

I5621.00 bodas, fiestas y otras celebraciones, buffet) en la localización especificada por el cliente (abastecedores de eventos)

I5629.01 Actividades de contratistas de servicio de comidas (por ejemplo, para compañías de transporte catering)

Servicios de concesiones de servicio de comidas en instalaciones deportivas e instalaciones

I5629.02 similares, cantinas o cafeterías (por ejemplo, para fábricas, oficinas, hospitales o escuelas) en régimen de concesión.

I5630.01 Actividades de preparación y servicio de bebidas para su consumo inmediato en: bares, tabernas, coctelerías, discotecas (con suministro predominante de bebidas) cervercerías y pubs.

I5630.02 Actividades de preparación y servicio de bebidas para su consumo inmediato en: cafés, tiendas de jugos de fruta, vendedores ambulantes de bebidas, etcétera.

Tabla: Elaboración propia.

Fuente de datos: (INEC, 2021).

\section{VENTAS}

Teniendo presente la clasificación y descripción de las actividades económicas, se presenta las ventas generadas por la Industria de Alojamiento y Servicio de Comidas y su participación frente a las ventas totales junto a su tasa de variación. 
Tabla 6. Ventas Totales de todas las Industrias vs. Ventas de la Industria de Alojamiento y Servicio de comida desde el 2011 al 2020

\begin{tabular}{|c|c|c|c|c|c|c|}
\hline \multicolumn{7}{|c|}{ Ventas Totales de todas las Industrias vs. Ventas de la Industria de Alojamiento y Servicios de Comida } \\
\hline Año & & Tentas Totales & \% de variación & Ventas Industria & \% de variación & \% de participación \\
\hline 2011 & $\$$ & $83,672,030,327$ & & $\$ 1,456,276,436$ & & $1.74 \%$ \\
\hline 2012 & $\$$ & $94,844,588,798$ & $13.35 \%$ & $\$ 1,701,638,926$ & $16.85 \%$ & $1.79 \%$ \\
\hline 2013 & $\$$ & $105,132,266,458$ & $10.85 \%$ & $\$ 1,953,134,849$ & $14.78 \%$ & $1.86 \%$ \\
\hline 2014 & $\$$ & $111,624,091,954$ & $6.17 \%$ & \$2,164,314,113 & $10.81 \%$ & $1.94 \%$ \\
\hline 2015 & $\$$ & $105,454,338,538$ & $-5.53 \%$ & $\$ 2,237,082,498$ & $3.36 \%$ & $2.12 \%$ \\
\hline 2016 & $\$$ & $95,509,409,045$ & $-9.43 \%$ & $\$ 2,040,522,614$ & $-8.79 \%$ & $2.14 \%$ \\
\hline 2017 & $\$$ & $102,802,846,252$ & $7.64 \%$ & $\$ 2,219,213,894$ & $8.76 \%$ & $2.16 \%$ \\
\hline 2018 & $\$$ & $108,702,250,146$ & $5.74 \%$ & $\$ 2,425,344,640$ & $9.29 \%$ & $2.23 \%$ \\
\hline 2019 & $\$$ & $108,184,828,118$ & $-0.48 \%$ & $\$ 2,520,161,461$ & $3.91 \%$ & $2.33 \%$ \\
\hline 2020 & $\$$ & $84,994,382,946$ & $-21.44 \%$ & $\$ 1,487,936,336$ & $-40.96 \%$ & $1.75 \%$ \\
\hline Total & & $000,921,032,582$ & & $\$ 20,205,625,767$ & & $2.02 \%$ \\
\hline
\end{tabular}

Tabla: Elaboración propia.

Fuente de datos: (SAIKU, SRI, 2021)

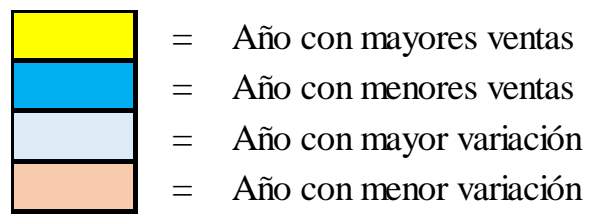

Los datos expuestos en la tabla \#6 demuestran que las Ventas generadas desde el año 2011 al 2020 por todas las actividades económicas fueron de alrededor de un trillón y que el año 2014 fue el que obtuvo mayores ventas y el año 2011 con menores ventas seguida por el 2020.

Asimismo, la Industria generó un total de ventas durante el período mencionado de aproximadamente 20 billones representando así el 2.02\%. El año con mayores ventas para la Industria fue el año 2019 y su año con menores ventas fue el año 2011 seguida por el año 2020.

El año 2012 tuvo el mayor porcentaje de variación tanto de las ventas totales como de la Industria, siendo este alrededor del 14\%. Así también para el año 2020 se evidencia los efectos colaterales de la pandemia, y en este caso para las ventas totales hubo una reducción del $21.44 \%$ y de la Industria del $40.96 \%$.

Existe un total de 21 Industrias de las cuales la Industria de Alojamiento y Servicio de Comidas aportó en promedio con un $2.01 \%$ de las ventas totales. 
Tabla 7. Ventas generadas por las Actividades Económicas del Sector de Alojamiento desde el 2011 al 2020

\begin{tabular}{|c|c|c|c|c|c|c|c|c|c|}
\hline \multicolumn{10}{|c|}{ Ventas del Sector de Alojamiento } \\
\hline Año/Act. & & I5510.01 & & I5510.02 & I5510.09 & I5520.00 & I5590.01 & Total Sector & \% de variación \\
\hline 2011 & $\$$ & $326,483,450$ & $\$$ & $24,634,602$ & $\$ 19,475,945$ & $\$ 1,631,508$ & $\$ 160,281$ & $\$ 372,385,786$ & \\
\hline 2012 & $\$$ & $363,549,946$ & $\$$ & $28,237,265$ & $\$ 20,415,988$ & $\$ 1,856,826$ & $\$ 216,015$ & $\$ 414,276,040$ & $11.25 \%$ \\
\hline 2013 & $\$$ & $399,274,434$ & $\$$ & $29,722,974$ & $\$ 22,939,726$ & $\$ 1,835,060$ & $\$ 162,538$ & $\$ 453,934,732$ & $9.57 \%$ \\
\hline 2014 & $\$$ & $427,383,855$ & $\$$ & $31,017,461$ & $\$ 26,091,327$ & $\$ 1,930,010$ & $\$ 225,214$ & $\$ 486,647,867$ & $7.21 \%$ \\
\hline 2015 & $\$$ & $411,965,367$ & $\$$ & $33,302,379$ & $\$ 27,500,852$ & $\$ 1,481,096$ & $\$ 178,862$ & $\$ 474,428,556$ & $-2.51 \%$ \\
\hline 2016 & $\$$ & $350,369,743$ & $\$$ & $32,663,998$ & $\$ 26,297,418$ & $\$ 1,119,873$ & \$ 140,964 & \$ 410,591,996 & $-13.46 \%$ \\
\hline 2017 & $\$$ & $364,055,953$ & $\$$ & $35,168,245$ & $\$ 29,582,968$ & $\$ 1,230,481$ & $\$ 144,931$ & $\$ 430,182,578$ & $4.77 \%$ \\
\hline 2018 & $\$$ & $401,899,190$ & $\$$ & $38,308,033$ & $\$ 35,105,502$ & $\$ 1,507,003$ & $\$ 117,942$ & $\$ 476,937,670$ & $10.87 \%$ \\
\hline 2019 & $\$$ & $407,320,986$ & $\$$ & $40,764,743$ & $\$ 37,214,204$ & $\$ 1,744,295$ & $\$ 131,884$ & $\$ 487,176,112$ & $2.15 \%$ \\
\hline 2020 & $\$$ & $174,130,186$ & $\$$ & $27,906,095$ & $\$ 17,606,241$ & 891,449 & 50,411 & $\$ 220,584,382$ & $-54.72 \%$ \\
\hline Total & & $, 626,433,110$ & & $321,725,795$ & $\$ 262,230,171$ & $\$ 15,227,601$ & $\$ 1,529,042$ & $\$ 4,227,145,719$ & \\
\hline
\end{tabular}

Fuente de datos: (SAIKU, SRI, 2021)

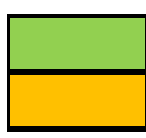

$=\quad$ Actividad con mayores ventas

$=$ Actividad con menores ventas

$\square=$ Año con mayor variación
$=$ Año con menor variación

En la tabla \#7 se puede observar las ventas generadas por las actividades económicas del sector de Alojamiento y se pudo conocer que el año 2012 tuvo la mayor variación con un $11.25 \%$ de crecimiento a comparación del año anterior y que el año 2020 fue el más afectado ya que hubo un decrecimiento de sus ventas del - 54.72\%. Además, se pudo conocer que la Actividad I5510.01, es decir, "Servicios de Alojamiento prestados por hoteles, hoteles de suites, apart hoteles, complejos turísticos y hosterías" es la que ha generado mayores ventas dentro de este sector y que la Actividad "I5590.01" cuyo código representa a la actividad "Servicios de residencias de estudiantes, dormitorios escolares, albergues para trabajadores, casas de huéspedes e internados" es la que menos ventas ha generado y su participación ha sido inferior a las demás durante los 10 años.

Ciencia Latina Revista Científica Multidisciplinar, Ciudad de México, México. ISN 2707-2207 / ISSN 2707-2215 (en línea), noviembre-diciembre, 2021, Volumen 5, Nún https://doi.org/10.37811/cl_rcm.v5i6.1317 p13224 
Tabla 8. Ventas generadas por las Actividades Económicas del sector de Servicio de Comidas desde el 2011 al 2020

\begin{tabular}{|c|c|c|c|c|c|c|c|c|c|c|c|c|c|c|c|c|c|c|}
\hline \multicolumn{19}{|c|}{ Ventas del Sector de Servicio de Comidas } \\
\hline Año/Act. & & I5610.01 & & I5610.02 & & I5610.03 & & 3610.04 & & I5621.00 & & I5629.01 & & 5629.02 & I5630.01 & I5630.02 & Total Sector & \% de variación \\
\hline 2011 & $\$$ & $708,749,474$ & $\$$ & $92,163,979$ & $\$$ & $12,923,170$ & $\$$ & 2,203 & $\$$ & $133,864,284$ & $\$$ & $12,105,057$ & $\$$ & 667,159 & $\$ 39,137,855$ & $\$ 84,277,469$ & $\$ 1,083,890,650$ & \\
\hline 2012 & $\$$ & $829,271,288$ & $\$$ & $107,166,676$ & $\$$ & $11,311,542$ & $\$$ & 2,115 & $\$$ & $166,986,019$ & $\$$ & $19,838,901$ & $\$$ & 618,237 & $\$ 48,671,062$ & $\$ 103,497,046$ & $\$ 1,287,362,886$ & $18.77 \%$ \\
\hline 2013 & $\$$ & $964,005,012$ & $\$$ & $119,301,383$ & $\$$ & $13,802,887$ & $\$$ & 9,158 & $\$$ & $203,681,461$ & $\$$ & $27,040,193$ & $\$$ & 976,704 & $\$ 42,589,017$ & $\$ 127,794,302$ & $\$ 1,499,200,117$ & $16.46 \%$ \\
\hline 2014 & $\$$ & $1,103,375,693$ & $\$$ & $128,760,429$ & $\$$ & $14,394,155$ & $\$$ & 6,162 & $\$$ & $227,479,264$ & $\$$ & $29,263,883$ & $\$$ & $1,661,712$ & $\$ 38,882,623$ & $\$ 133,842,325$ & $\$ 1,677,666,246$ & $11.90 \%$ \\
\hline 2015 & $\$$ & $1,171,769,377$ & $\$$ & $134,973,919$ & $\$$ & $13,009,612$ & $\$$ & 75,743 & $\$$ & $239,471,784$ & $\$$ & $33,657,994$ & $\$$ & $2,090,386$ & $\$ 37,855,199$ & $\$ 129,749,928$ & $\$ 1,762,653,942$ & $5.07 \%$ \\
\hline 2016 & $\$$ & $1,108,446,200$ & $\$$ & $130,487,830$ & $\$$ & $11,730,702$ & $\$$ & 97,479 & $\$$ & $204,805,900$ & $\$$ & $38,354,123$ & $\$$ & $2,303,128$ & $\$ 32,536,146$ & $\$ 101,169,110$ & $\$ 1,629,930,618$ & $-7.53 \%$ \\
\hline 2017 & $\$$ & $1,183,367,248$ & $\$$ & $140,205,417$ & $\$$ & $13,982,374$ & $\$$ & 99,974 & $\$$ & $279,235,515$ & $\$$ & $41,558,340$ & $\$$ & $3,758,525$ & $\$ 34,835,204$ & \$ 91,988,719 & $\$ 1,789,031,316$ & $9.76 \%$ \\
\hline 2018 & $\$$ & $1,303,284,312$ & $\$$ & $153,159,667$ & $\$$ & $14,898,806$ & $\$$ & 420,094 & $\$$ & $297,568,074$ & $\$$ & $50,358,389$ & $\$$ & $7,095,705$ & $\$ 35,114,438$ & $\$ 86,507,485$ & $\$ 1,948,406,970$ & $8.91 \%$ \\
\hline 2019 & $\$$ & $1,353,165,733$ & $\$$ & $172,358,814$ & $\$$ & $15,510,524$ & $\$$ & 476,782 & $\$$ & $302,326,868$ & $\$$ & $55,646,223$ & & $6,039,573$ & $\$ 35,148,062$ & $\$ 82,312,770$ & $\$ 2,032,985,349$ & $4.34 \%$ \\
\hline 2020 & $\$$ & $842,934,830$ & $\$$ & $112,933,127$ & $\$$ & $10,982,941$ & $\$$ & 255,113 & $\$$ & $193,114,444$ & $\$$ & $35,695,132$ & & $3,420,980$ & $\$ 11,107,119$ & $\$ 46,908,268$ & \$ $1,267,351,954$ & $-37.66 \%$ \\
\hline Total & & $10,568,369,167$ & & ,291,511,241 & & $32,546,713$ & & $, 444,823$ & & ,248,533,613 & & $43,518,235$ & & $8,632,109$ & $\$ 355,876,725$ & $\$ 988,047,422$ & $\$ 15,978,480,048$ & \\
\hline
\end{tabular}
Tabla: Elaboración propia. Fuente de datos: (SAIKU, SRI, 2021)
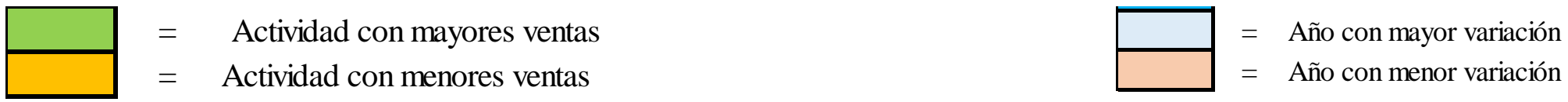

Por otra parte, en la tabla \#8 se presenta las ventas de las actividades económicas del sector de Servicios de Comida y asimismo se pudo conocer que el año con mayor crecimiento fue el 2012 y el año 2020 arraigado a las consecuencias del COVID-19 fue el más afectado con una caída en sus ventas del $37.66 \%$, sin embargo, si se compara con el sector de Alojamiento se puede deducir que el sector de Servicio de Comidas fue el menos afectado en sus ventas debido a que fue una de los sectores que a pesar de la cuarentena establecida por el gobierno siguió operando para realizar entregas a domicilio. La actividad con mayores ventas generadas es la I5610.10 que representa a "Restaurantes, cevicherías, picanterías, cafeterías, etcétera, incluido comida para llevar" con una diferencia considerable a comparación de las otras actividades. Por el contrario, la actividad "Servicios de restaurantes, y bares en conexión con transporte cuando son proporcionadas por unidades independientes: bares del aeropuerto, bares terminales terrestres, etcétera" cuyo código es I5610.04, fue la que generó menores ventas durante el período 2011 al 2020.

Ciencia Latina Revista Científica Multidisciplinar, Ciudad de México, México. ISN 2707-2207 / ISSN 2707-2215 (en línea), noviembre-diciembre, 2021, Volumen 5, Nún https://doi.org/10.37811/cl rcm.v5i6.1317 p13225 
Es importante mencionar que la actividad I5610.01 no solamente es la que mayores ventas ha generado dentro del sector de Servicio de Comidas sino también a nivel Industrial, siendo esta una actividad clave y estratégica para dinamizar la economía y ser la mayor fuente para la Industria de Alojamiento y Servicio de Comidas; así también la actividad I5610.04 es la que menores ventas ha tenido a nivel de Industria.

Tabla 9. Ventas generadas por Sector vs. Ventas generadas por la Industria de Alojamiento y Servicio de Comidas desde el 2011 al 2020

\begin{tabular}{lcc}
\hline \multicolumn{3}{c}{ Ventas desde el 2011 al 2020 } \\
\hline Total Alojamiento & $\$ 4,227,145,719$ & $20.92 \%$ \\
Total Servicios de Comida & $\$ 15,978,480,048$ & $79.08 \%$ \\
Total Industria & $\mathbf{\$ 2 0 , 2 0 5 , 6 2 5 , 7 6 7}$ & $\mathbf{1 0 0 . 0 0 \%}$ \\
\hline
\end{tabular}

Tabla: Elaboración propia.

Fuente de datos: (SAIKU, SRI, 2021)

En la tabla \#9 se sintetiza el total de ventas por parte de Alojamiento y Servicio de Comidas y el total de la Industria durante el año 2011 al 2020 y cuyo resultado fue que el sector de Servicio de Comidas tuvo mayor participación a comparación de Alojamiento, ya que este fue del $79.08 \%$.

\section{CONCLUSIONES}

La Industria de Alojamiento y Servicios de Comida durante el año pandémico 2020 representó el 2.16\% del PIB del país cuyo decrecimiento frente al año 2019 fue del $-11.70 \%$.

Durante el período 2018 - 2020, la Industria de Alojamiento y Servicios de Comida ha tenido una Recaudación Tributaria de $\$ 449,941,219$ y ha generado un total de ventas en estos últimos tres años de $\$ 6,433,442,437$.

La Recaudación Tributaria a nivel país para el año 2020 fue de \$11,526,978,000 de los cuales el $1.04 \%$ perteneció a la Industria de Alojamiento y Servicios de comida. La pandemia afectó en la recaudación de impuestos dado que a nivel nacional hubo un impacto negativo del $-22.50 \%$ y a nivel de Industria del $-28.53 \%$ en referencia al año 2019.

El Sector de Alojamiento fue el más afectado durante el año 2020 a comparación de Servicios de Comida, del total de recaudación de impuestos este sector representó el $14.79 \%$ con un decrecimiento del $-46.05 \%$, así como también del total de ventas de la Industria representó el 14.82\%.con un decrecimiento del - 54.72\%. 
Las Ventas generadas en el 2020 por todas las industrias que conforman el aparato productivo del país fue de $\$ 84,994,382,946$ y que apenas el $1.75 \%$ fue representado por la Industria de Alojamiento y Servicios de Comida; en este año también se evidenció un decrecimiento a nivel país del- $21.44 \%$ y a nivel Industria del $-40.96 \%$.

\section{LISTA DE REFERNCIAS}

Banco Central de Ecuador . (30 de Septiembre de 2020). Banco Central del Ecuador. Obtenido de https://www.bce.fin.ec/index.php/boletines-de-prensaarchivo/item/1383-la-economia-ecuatoriana-decrecio-12-4-en-el-segundotrimestre-de2020\#: :text=En\%20el\%20contexto\%20de\%20la,y\%2C\%20iv)\%20contracci\% C3\%B3n\%20de\%2010

Banco Central del Ecuador. (2020). PIB Y VAB por Industrias. Obtenido de https://www.bce.fin.ec/index.php/informacioneconomica

Banco Central del Ecuador. (2020). Producto Interno Bruto por Industria. Obtenido de https://contenido.bce.fin.ec/documentos/PublicacionesNotas/Catalogo/IEMensua 1/m1969/IEM-432.xls

Banco Mundial. (2020). Banco Mundial. Obtenido de PIB: https://datos.bancomundial.org/indicator/NY.GDP.MKTP.KD.ZG?locations=EC Ekos Negocios. (2019). Ekos Negocios. Obtenido de https://www.ekosnegocios.com/sector/restaurantes-y-comida-rapida

El Telégrafo. (29 de Diciembre de 2020). El Telégrafo. Obtenido de https://www.eltelegrafo.com.ec/noticias/punto-de-vista/3/que-significo-el-2020para-la-economia-del-pais

$\begin{array}{lllll}\text { INEC. } & \text { (2021). } & \text { Obtenido } & \text { de }\end{array}$ https://aplicaciones2.ecuadorencifras.gob.ec/SIN/resul_ciiu4_co.php?select=val ue \&busqueda $=\mathrm{I} \&$ Buscar $=$ Buscar + Por $+\mathrm{C} \% \mathrm{~F} 3$ digo

Lucero, K. (22 de Abril de 2020). Revista Gestión. Obtenido de https://www.revistagestion.ec/economia-y-finanzas-analisis/el-coronaviruspuso-al-turismo-contra-las-cuerdas

Ministerio de Turismo. (2020). Catastro de Servicios Turísticos. Obtenido de Visualizador del número de establecimientos registrados: 
https://servicios.turismo.gob.ec/index.php/turismo-cifras/2018-09-18-21-1117/establecimientos-registrados

Orozco, M. (07 de Enero de 2021). SRI recaudó USD 12382 millones en el 2020; en diciembre se recaudó más por IVA. EL COMERCIO.

Planifica Ecuador. (Mayo de 2020). Planifica Ecuador. Obtenido de Evaluación Socioeconómica: https://www.planificacion.gob.ec/wpcontent/uploads/downloads/2020/12/Eval-Soc-Econ-10-Dic-ok.pdf

SAIKU, SRI. (2021). Servicio de Rentas Internas. Obtenido de Declaraciones 104: https://srienlinea.sri.gob.ec/saiku-ui/

Sánchez, A., Vayas, T., Mayorga, F., \& Freire, C. (2020). Universidad Técnica de Ambato. Obtenido de https://blogs.cedia.org.ec/obest/wpcontent/uploads/sites/7/2020/06/Turismo-en-Ecuador-Alojamiento-y-serviciosde-comida.pdf

SRI. (2020). SRI. Obtenido de Recaudación de Gestión: https://www.sri.gob.ec/estadisticas-generales-de-recaudacion-sri 


\section{Anexos}

Anexo 1. VAB por Industrias y PIB Ecuador por trimestres año 2011

\begin{tabular}{|c|c|c|c|c|c|c|c|}
\hline \multicolumn{8}{|c|}{2011} \\
\hline Nro. & INDUSTRIA / PERIODO & $\mathbf{T 1}$ & $\mathbf{T} 2$ & $\mathbf{T 3}$ & T4 & Total & $\%$ \\
\hline 1 & Petróleo y minas & $\$ 2,474,753$ & $\$ 2,711,035$ & $\$ 2,471,299$ & $\$ 2,805,769$ & $\$ 10,462,856$ & $13.20 \%$ \\
\hline 2 & $\begin{array}{c}\text { Manufactura (excepto refinación de } \\
\text { petróleo) }\end{array}$ & $\$ 2,346,118$ & $\$ 2,412,154$ & $\$ 2,445,560$ & $\$ 2,466,615$ & $\$ 9,670,447$ & $12.20 \%$ \\
\hline 3 & Comercio & $\$ 1,991,860$ & $\$ 2,080,496$ & $\$ 2,139,717$ & $\$ 2,187,743$ & $\$ 8,399,816$ & $10.60 \%$ \\
\hline 4 & Construcción & $\$ 1,853,519$ & $\$ 1,964,192$ & $\$ 2,100,585$ & $\$ 2,188,198$ & $\$ 8,106,494$ & $10.23 \%$ \\
\hline 5 & Agricultura & $\$ 1,623,868$ & $\$ 1,634,715$ & $\$ 1,687,046$ & $\$ 1,756,802$ & $\$ 6,702,431$ & $8.45 \%$ \\
\hline 6 & Enseñanza Servicios sociales y de salud & $\$ 1,459,734$ & $\$ 1,478,880$ & $\$ 1,487,691$ & $\$ 1,569,541$ & $\$ 5,995,846$ & $7.56 \%$ \\
\hline 7 & Otros Servicios (*) & $\$ 1,231,152$ & $\$ 1,256,126$ & $\$ 1,281,635$ & $\$ 1,294,907$ & $\$ 5,063,820$ & $6.39 \%$ \\
\hline 8 & $\begin{array}{c}\text { Actividades profesionales, técnicas y } \\
\text { administrativas }\end{array}$ & $\$ 1,160,593$ & $\$ 1,234,262$ & $\$ 1,308,491$ & $\$ 1,343,075$ & $\$ 5,046,421$ & $6.37 \%$ \\
\hline 9 & $\begin{array}{c}\text { Administración pública, defensa; planes } \\
\text { de seguridad social obligatoria }\end{array}$ & $\$ 1,147,385$ & $\$ 1,285,401$ & $\$ 1,272,434$ & $\$ 1,308,248$ & $\$ 5,013,468$ & $6.32 \%$ \\
\hline 10 & Transporte & 906,639 & 921,453 & 931,522 & 936,733 & $\$ 3,696,347$ & $4.66 \%$ \\
\hline 11 & Actividades de servicios financieros & 532,828 & 557,038 & 590,019 & 620,570 & $\$ 2,300,455$ & $2.90 \%$ \\
\hline 12 & Correo y Comunicaciones & 449,621 & 452,287 & 450,377 & 459,530 & $\$ 1,811,815$ & $2.29 \%$ \\
\hline 13 & Alojamiento y servicios de comida & 334,411 & 352,917 & 363,506 & 377,055 & $\$ 1,427,889$ & $1.80 \%$ \\
\hline 14 & Suministro de electricidad y agua & 202,619 & 229,780 & 246,302 & 248,954 & 927,655 & $1.17 \%$ \\
\hline 15 & Refinación de Petróleo & 214,157 & 171,921 & 165,334 & 116,623 & 668,035 & $0.84 \%$ \\
\hline 16 & Pesca (excepto camarón) & 105,595 & 113,064 & 143,351 & 126,107 & 488,117 & $0.62 \%$ \\
\hline 17 & Acuicultura y pesca de camarón & 96,173 & 105,197 & 109,391 & 110,136 & 420,897 & $0.53 \%$ \\
\hline 18 & Servicio doméstico & 84,724 & 83,278 & 83,459 & 81,945 & 333,406 & $0.42 \%$ \\
\hline & Total Valor Agregado Bruto & $\$ 18,215,749$ & $\$ 19,044,196$ & $\$ 19,277,719$ & $\$ 19,998,551$ & $\$ 76,536,215$ & $96.54 \%$ \\
\hline & Otros Elementos del PIB (**) & 707,206 & 683,918 & 690,751 & 658,574 & $\$ 2,740,449$ & $3.46 \%$ \\
\hline & PIB (***) & $\$ 18,922,955$ & $\$ 19,728,114$ & $\$ 19,968,470$ & $\$ 20,657,125$ & $\$ 79,276,664$ & $100.00 \%$ \\
\hline
\end{tabular}

Anexo: Elaboración propia.

Fuente de datos: (Banco Central del Ecuador, 2020) 
Anexo 2. VAB por Industrias y PIB Ecuador por trimestres año 2013

\begin{tabular}{|c|c|c|c|c|c|c|c|}
\hline \multicolumn{8}{|c|}{2013} \\
\hline Nro & INDUSTRIA / PERIODO & T1 & $\mathbf{T} 2$ & $\mathbf{T 3}$ & T4 & Total & $\%$ \\
\hline 1 & $\begin{array}{c}\text { Manufactura (excepto refinación de } \\
\text { petróleo) }\end{array}$ & $2,851,917$ & $2,950,488$ & $3,047,191$ & $3,124,695$ & $11,974,291$ & $12.59 \%$ \\
\hline 2 & Petróleo y minas & $2,990,265$ & $2,892,812$ & $3,091,849$ & $2,876,240$ & $11,851,166$ & $12.46 \%$ \\
\hline 3 & Construcción & $2,448,769$ & $2,483,745$ & $2,529,185$ & $2,550,964$ & $10,012,663$ & $10.53 \%$ \\
\hline 4 & Comercio & $2,416,809$ & $2,475,767$ & $2,530,737$ & $2,553,333$ & $9,976,646$ & $10.49 \%$ \\
\hline 5 & Enseñanza Servicios sociales y de salud & $1,811,667$ & $1,870,645$ & $1,894,100$ & $1,937,034$ & $7,513,446$ & $7.90 \%$ \\
\hline 6 & Agricultura & $1,740,048$ & $1,777,310$ & $1,816,142$ & $1,897,202$ & $7,230,702$ & $7.60 \%$ \\
\hline 7 & $\begin{array}{c}\text { Actividades profesionales, técnicas y } \\
\text { administrativas }\end{array}$ & $1,555,030$ & $1,612,390$ & $1,662,416$ & $1,719,941$ & $6,549,777$ & $6.89 \%$ \\
\hline 8 & $\begin{array}{l}\text { Administración pública, defensa; } \\
\text { planes de seguridad social obligatoria }\end{array}$ & $1,471,983$ & $1,500,765$ & $1,538,264$ & $1,539,900$ & $6,050,912$ & $6.36 \%$ \\
\hline 9 & Otros Servicios $(*)$ & $1,367,612$ & $1,391,931$ & $1,406,182$ & $1,426,850$ & $5,592,575$ & $5.88 \%$ \\
\hline $\mathbf{1 0}$ & Transporte & $1,033,022$ & $1,062,576$ & $1,087,927$ & $1,116,037$ & $4,299,562$ & $4.52 \%$ \\
\hline 11 & Correo y Comunicaciones & 494,802 & 501,882 & 508,242 & 516,559 & $2,021,485$ & $2.12 \%$ \\
\hline 12 & Actividades de servicios financieros & 646,04 & 636,564 & 643,431 & 664,518 & $1,944,513$ & $2.04 \%$ \\
\hline 13 & Alojamiento y servicios de comida & 446,433 & 463,333 & 477,43 & 490,366 & $1,400,132$ & $1.47 \%$ \\
\hline 14 & Suministro de electricidad y agua & 279,23 & 246,885 & 284,557 & 254,856 & 786,298 & $0.83 \%$ \\
\hline 15 & Pesca (excepto camarón) & 129,366 & 156,811 & 161,915 & 147,813 & 595,905 & $0.63 \%$ \\
\hline 16 & Acuicultura y pesca de camarón & 114,691 & 128,235 & 130,314 & 142,399 & 515,639 & $0.54 \%$ \\
\hline 17 & Refinación de Petróleo & 50,212 & 48,666 & 162,064 & 172,395 & 433,337 & $0.46 \%$ \\
\hline 18 & Servicio doméstico & 91,115 & 94,863 & 96,986 & 99,149 & 382,113 & $0.40 \%$ \\
\hline & Total Valor Agregado Bruto & $21,939,011$ & $22,295,668$ & $23,068,932$ & $23,230,251$ & $90,533,862$ & $95.17 \%$ \\
\hline & Otros Elementos del PIB $(* *)$ & $1,080,775$ & $1,145,656$ & $1,169,644$ & $1,199,722$ & $4,595,797$ & $4.83 \%$ \\
\hline & PIB $(* * *)$ & $23,019,786$ & $23,441,324$ & $24,238,576$ & $24,429,973$ & $95,129,659$ & $100.00 \%$ \\
\hline
\end{tabular}

Anexo: Elaboración propia.

Fuente de datos: (Banco Central del Ecuador, 2020) 